\title{
SYNTHESIS OF Co-NH $/$ MESOPOROUS SILICA BIFUNCTIONAL CATALYST USING SIDOARJO MUD AND BOVINE BONE GELATIN TEMPLATE FOR CONVERSION OF USED COOKING OIL INTO BIOFUEL
}

\author{
W. Trisunaryanti ${ }^{1, *}$, Triyono ${ }^{1}$ and D. A. Fatmawati ${ }^{1}$ \\ ${ }^{1}$ Department of Chemistry, Faculty of Mathematics and Natural Sciences, \\ Universitas Gadjah Mada, Sekip Utara Bulaksumur Yogyakarta, 55281, Indonesia \\ *E-mail: wegats@ugm.ac.id
}

\begin{abstract}
Synthesis of Co- $\mathrm{NH}_{2} /$ mesoporous silica bifunctional catalyst for conversion of used cooking oil into biofuel was carried out. Synthesis of mesoporous silica (MS) was done by the hydrothermal method using silica from Sidoarjo mud and gelatin from bovine bone as a template. Weight ratio variation of silica/gelatin was 4,6 , and 8 produced MS4, MS6, and MS8 respectively characterized by FTIR. The MS with minimum gelatin content after calcination (MS8) was identified using FTIR, TEM, and SAA. The impregnation of Co into the MS8 was done by the wet impregnation method and the Co/MS8 catalyst was analyzed using XRF and acidity test with $\mathrm{NH}_{3}$ vapor adsorption. Functionalization of $\mathrm{NH}_{2}$ into the MS8 and Co/MS8 was done by the grafting method and the products were characterized using FTIR. The catalytic activity test in used cooking oil hydrocracking was done by thermal (without catalyst), physical mixture of $\mathrm{Co} / \mathrm{MS} 8$ and $\mathrm{NH}_{2} / \mathrm{MS} 8$ catalyst, and $\mathrm{Co}-\mathrm{NH}_{2} / \mathrm{MS} 8$ bifunctional catalyst. The hydrocracking liquid products were investigated by GC-MS. The MS8 had a specific surface area of $666.76 \mathrm{~m}^{2} \mathrm{~g}^{-1}$, a pore diameter of $4.9 \mathrm{~nm}$, and a pore volume of $0.46 \mathrm{~cm}^{3} \mathrm{~g}^{-1}$. The Co- $\mathrm{NH}_{2} / \mathrm{MS} 8$ bifunctional catalyst produced the highest liquid product of $97.62 \mathrm{wt} \%$ in the hydrocracking of used cooking oil with selectivity for gasoline and diesel fraction of 3.02 and 46.86 wt. $\%$.
\end{abstract}

Keywords: Bifunctional Catalyst, Biofuel, Gelatin, Mesoporous Silica, Sidoarjo Mud

(C) RASĀYAN. All rights reserved

\section{INTRODUCTION}

Research on the synthesis of mesoporous silica (MS) ${ }^{1,2}$ as MCM- $41^{2}$ and SBA- $15^{4}$ has been carried out widely. However, most of the used silica is synthetic silica (TEOS, TMOS, sodium silicate, etc) which is less green material. Therefore, synthetic silica is replaced with the extracted silica from natural materials such as fly ash, rice husk, and mud. ${ }^{5}$ Based on research, the highest component of Sidoarjo mud is silica. ${ }^{6}$ One important factor in the synthesis of mesoporous material is the selection of a template. A cationic surfactant such as Cetyl Trimethyl Ammonium Bromide (CTAB) is often used as a template in the synthesis of MCM-41. ${ }^{7}$ However, the type of surfactant is difficultly degradable and can cause environmental pollution. Neutral surfactant is more easily degraded in nature so it is a more friendly environment. One of the neutral surfactants that can be used as a template in the synthesis of MS material is gelatin. ${ }^{8}$ Gelatin can be extracted from natural materials such as bovine bone. ${ }^{9}$ Gelatin contains many amine groups $\left(-\mathrm{NH}_{2}\right)$ that have a high affinity for interacting firmly with silanol (Si-OH) groups in silica groups through collective hydrogen bonds. ${ }^{1}$

Generally, the MS is synthesized using hydrothermal method. ${ }^{10}$ The MS contained only pure silica material which has a weak Lewis acid site, so it is difficult to be used directly as a catalyst and adsorbent. Lewis acid site will be increased if the structure of the MS is embedded in a transition metal. ${ }^{11,12}$ Impregnation of transition metals such as cobalt can increase acidity by giving Lewis acid sites to the carrier material. ${ }^{13}$ This is because cobalt has empty d orbitals that can accept electrons. Heterogeneous catalysts still have a disadvantage that feared the occurrence of leaching metal or compound in the MCM-

Rasayan J. Chem., 13(1), 723-732(2020)

http://dx.doi.org/10.31788/RJC.2020.1315514




RASĀYAN J. Chem.

Vol. 13 | No. 1 |723-732| January - March | 2020

41. Prevention of leaching needs the modification of catalyst which has active sites bonded strongly in MCM-41 such as amino-silane. ${ }^{14}$ The combination of these materials (cobalt metal, amine group, and mesoporous silica) results in a Co- $\mathrm{NH}_{2} / \mathrm{MS}$ catalyst which will be tested for its activity in used cooking oil hydrocracking.

Used cooking oil contains free fatty acids which is one of the potential biofuel feedstocks to be used in Indonesia. The conversion of used cooking oil is the most important process to provide a new and renewable energy source. ${ }^{15}$ Based on Kandel and co-workers' research, $\mathrm{Ni}-\mathrm{NH}_{2} / \mathrm{MS}$ catalyst had selectivity to capture the free fatty acids and convert them into hydrocarbons. ${ }^{16}$ The study reported that the $\mathrm{Ni}-\mathrm{NH}_{2} / \mathrm{MS}$ catalyst as bifunctional material yielded $72 \mathrm{wt} \%$ conversion of the oleic acid in the microalgae oil into liquid hydrocarbons. However, the materials used are Tetramethyl Orthosilicate (TMOS) as a source of silica and neutral block copolymer pluronic P104 surfactants as a template. Both of these materials are synthetic so they are less green materials.

Based on the description above, the author will synthesize $\mathrm{Co}-\mathrm{NH}_{2} / \mathrm{MS}$ based on silica extracted by Sidoarjo mud and template from gelatin extracted by bovine bone to produce the catalyst of hydrocracking process in used cooking oil into gasoline and diesel fraction.

\section{Materials}

\section{EXPERIMENTAL}

There is Lapindo mud produced in Sidoarjo, bovine bone from the Yogyakarta market, $\mathrm{NaOH}$ (p.a), $\mathrm{HCl}$ $37 \%$ (p.a), $\mathrm{Co}\left(\mathrm{NO}_{3}\right)_{2} \bullet 6 \mathrm{H}_{2} \mathrm{O}$, amine group from 3-aminopropyl trimethoxysilane (3-APTMS), toluene, methanol, acetic acid $100 \%$ (p.a), and sulfuric acid 98\% (p.a). All chemical materials are obtained from E-Merck (Germany). Besides, there are aquadest, aquabidest, and used cooking oil.

\section{Extraction of Silica from Sidoarjo Mud}

The extraction of silica was accomplished according to Triyono et al research ${ }^{17}$. The Sidoarjo mud was cleaned and washed with aquadest and dried. The Sidoarjo mud was sieved up to 100 mesh. $100 \mathrm{~g}$ of Sidoarjo mud was refluxed with $250 \mathrm{~mL}$ of $6 \mathrm{M} \mathrm{HCl}$ solution for $3 \mathrm{~h}$ at $90{ }^{\circ} \mathrm{C}$, then $300 \mathrm{~mL}$ of $6 \mathrm{M} \mathrm{NaOH}$ solution for $16 \mathrm{~h}$ (discontinue) at $90{ }^{\circ} \mathrm{C}$. The filtrate was disjoined from the solids by the filtration method. The $20 \mathrm{~mL}$ of supernatant was titrated using $3 \mathrm{M} \mathrm{HCl}$ solution up till $\mathrm{pH}$ 8. The white deposit was filtered out and cleaned with aquadest and heated for $24 \mathrm{~h}$ at $100^{\circ} \mathrm{C}$, producing $\mathrm{SiO}_{2}$ then analyzed using FTIR.

\section{Extraction of Gelatin From Bovine Bone}

The extraction of gelatin was based on Pongsendana et al research ${ }^{9}$. The bones were cleaned and washed with aquadest. Before gelatin extraction, the bovine bone was soaked in an acetic acid $4 \%$ with a bone/solution $(1: 2 \mathrm{w} / \mathrm{v})$ for $3 \mathrm{~d}$. After filtered, washed with aquadest until $\mathrm{pH} 5$, and dried, the sample was then pretreated with $\mathrm{NaOH} 1 \mathrm{M}$ by ratio $1: 6(\mathrm{w} / \mathrm{v})$ for $24 \mathrm{~h}$ and washed until $\mathrm{pH} 5$ again. After that, the sample was pretreated again with $1 \mathrm{M} \mathrm{HCl}$ by ratio $1: 3(\mathrm{w} / \mathrm{v})$ for $1 \mathrm{~h}$, followed by hydrolysis process using aquabidest with ratio $1: 4(\mathrm{w} / \mathrm{v})$ for $5 \mathrm{~h}$ at a temperature of $70^{\circ} \mathrm{C}$, filtered and dried in an oven at 50 ${ }^{\circ} \mathrm{C}$. The gelatin obtained was then characterized by FTIR.

\section{Synthesis of Mesoporous Silica (MS)}

The synthesis of mesoporous silica was based on Kusumastuti et al research ${ }^{11}$. The mesoporous silica materials (MS) were synthesized with variations of silica/gelatin weight ratios of 4, 6, and 8 to produce MS4, MS6, and MS8 respectively. Synthesis of MS4 was carried out by adding $1 \mathrm{~g}$ of gelatin dissolved in $25 \mathrm{~g}$ of aquabidest, stirred for $30 \mathrm{~m}$ and heated at $40{ }^{\circ} \mathrm{C}$ (solution 1). In the other polypropylene beaker, 2 $\mathrm{g}$ of $\mathrm{SiO}_{2}$ dissolved in $1.5 \mathrm{M} \mathrm{NaOH}$ solution (mole ratio of 1:2) to solve $\mathrm{Na}_{2} \mathrm{SiO}_{3}$. 4 g of sodium silicate solution dissolved in $25 \mathrm{~g}$ of aquabidest, stirred and heated at $40{ }^{\circ} \mathrm{C} .0 .1 \mathrm{M}$ Sulfuric acid was entered into the $\mathrm{Na}_{2} \mathrm{SiO}_{3}$ solution until pH 4 (Solution 2). Solution 2 was poured out to solution 1 and the mixture was stirred for $1 \mathrm{~h}$. The formed gel solution was transferred into an autoclave and hydrothermally carried out for $24 \mathrm{~h}$ at $100{ }^{\circ} \mathrm{C}$. Finally, the product was separated, cleaned with aquadest, heated at $80{ }^{\circ} \mathrm{C}$, analyzed by FTIR, and calcined for $5 \mathrm{~h}$ at $550^{\circ} \mathrm{C}$. The material was then investigated by FTIR and the MS with 
RASĀYAN J. Chem.

Vol. 13 | No. 1 |723 - 732| January - March | 2020

minimum gelatin content after calcination (MSx) was characterized by FTIR, SAA, and TEM. For the weight ratio of silica/gelatin 6 and 8 made also by following the same procedure.

\section{Synthesis of Co-MS Catalyst}

The MSx sample was poured into a $\mathrm{Co}\left(\mathrm{NO}_{3}\right)_{2} \bullet 6 \mathrm{H}_{2} \mathrm{O}$ solution $(0.2 \mathrm{~g}$ of salt precursor in $50 \mathrm{~mL}$ aquadest (8\% Co content)) while stirring for $24 \mathrm{~h}$, it was filtered, then dried in an oven at $70{ }^{\circ} \mathrm{C}$, followed by reduction with $\mathrm{H}_{2}$ gas at $450{ }^{\circ} \mathrm{C}$ for $3 \mathrm{~h}$ to produce $\mathrm{Co} / \mathrm{MSx}$ catalyst. The Co/MSx catalyst was characterized by XRF to analyze element content. Acidity was determined using $\mathrm{NH}_{3}$ vapor adsorption. Acidity means the total acid amount (mmol) calculated from $\mathrm{NH}_{3}$ vapor absorbed on the surface of solid/gram solid multiple by the molecular weight of ammonia.

\section{Synthesis of Co- $\mathrm{NH}_{2} / \mathrm{MS}$ Bifunctional Catalyst}

The 3-APTMS compound was refluxed in toluene solution for about $20 \mathrm{~m}$ at a temperature of $90{ }^{\circ} \mathrm{C}$. Each of the MSx and Co/MSx was calcined and added into the solution. The reflux process remained for $5 \mathrm{~h}$ at $90{ }^{\circ} \mathrm{C}$. The solid was separated from the solvent by centrifugation in $2000 \mathrm{rpm}$ for $20 \mathrm{~m}$. The solid was washed with toluene once followed by methanol twice. Then, it was dried for $24 \mathrm{~h}$ at $50{ }^{\circ} \mathrm{C}$ to result in $\mathrm{NH}_{2} / \mathrm{MSx}$ and $\mathrm{Co}-\mathrm{NH}_{2} / \mathrm{MSx}$ characterized using FTIR.

\section{Catalyst Activity Test}

The catalytic activity was tested in used cooking oil hydrocracking by thermal (without catalyst), physical mixture of $\mathrm{Co} / \mathrm{MSx}$ and $\mathrm{NH}_{2} / \mathrm{MSx}$ catalyst, and $\mathrm{Co}-\mathrm{NH}_{2} / \mathrm{MSx}$ bifunctional catalyst. The weight ratio of used cooking oil/catalyst was 5 . The catalyst activity tests were done in a stainless steel reactor $(1: 30 \mathrm{~cm}$, id: $1.6 \mathrm{~cm}$, od: $2 \mathrm{~cm}$ ) of the semi-batch system at $450{ }^{\circ} \mathrm{C}$ for $3 \mathrm{~h}$ under $\mathrm{H}_{2}$ gas flow. Products of hydrocracking consisted of liquid, coke, and gas fractions.

The liquid fraction (\%) $=$ (weight of the liquid/weight of the oil) $\mathrm{x} 100$.

The coke fraction $(\%)=$ deposited carbon on catalyst surface/weight of oil $\mathrm{x} 100$.

The gas fraction $(\%) \quad=[100-$ (liquid + coke) fractions $]$

The liquid product was analyzed by GC-MS. The selectivity of the catalysts (\%) toward gasoline (hydrocarbon compounds of $\mathrm{C}_{5}-\mathrm{C}_{12}$ ), diesel oil (hydrocarbon compounds of $\mathrm{C}_{13}-\mathrm{C}_{17}$ ) and others (compounds in the liquid fraction except gasoline and diesel oil) were calculated from the GC-MS area (\%) multiple by weight percent of liquid fraction.

\section{Detection Method}

The functional groups of all samples were determined using Fourier Transform Infrared spectrometer (FTIR, Shimadzu Prestige-21), Surface Area Analyzer (SAA, Quantachrome NovaWin2 1200e version 2.2) was used to determine the surface parameters (surface area, pore-volume, and pore diameter) of the sample. The pore morphology was taken using a Transmission Electron Microscope (TEM, JEOL JEM1400). The liquid produced by hydrocracking of used cooking oil was analyzed using gas chromatography-mass spectrometry (GC-MS, Shimadzu QP2010S). The acidity test of all samples was carried using the gravimetric method with ammonia vapor as the adsorbate. The sample was aged in the desiccator for $24 \mathrm{~h}$. The increase in the weight of the sample was measured to determine the amount of ammonia vapor bound to the sample. The metal content of the samples was analyzed by X-ray Fluorescence (XRF, PANalytical MiPal 4).

\section{Characterization of Silica from Sidoarjo Mud}

\section{RESULTS AND DISCUSSION}

Fig.-1 shows are characteristic of the FTIR absorption bond for the extraction of silica from Sidoarjo mud. It had the bending vibration of Si-O-Si at a wavenumber of $470 \mathrm{~cm}^{-1}$, symmetry stretching vibration of Si-O-Si at a wavenumber of $802 \mathrm{~cm}^{-1}$, asymmetry stretching vibration of Si-O-Si at a wavenumber of $1096 \mathrm{~cm}^{-1}$, bending vibration of Si-OH at a wavenumber of $1636 \mathrm{~cm}^{-1}$, and stretching vibration of Si-OH at a wavenumber of $3449 \mathrm{~cm}^{-1}$. 
RASĀYAN $J$. Chem.

Vol. 13 | No. 1 |723-732| January - March | 2020

In general, the absorption bands appearing on the spectrum of silica were silanol $(\mathrm{Si}-\mathrm{OH})$ and siloxane groups $(\mathrm{Si}-\mathrm{O}-\mathrm{Si})$. This research on silica extraction from Sidoarjo mud proves that it can be repeated the application of silica extraction methods according to what has been done by the previous researchers ${ }^{17,18}$. The interpretation of the FTIR result shows silica successfully extracted from the mud as it had a functional group typical of silica.

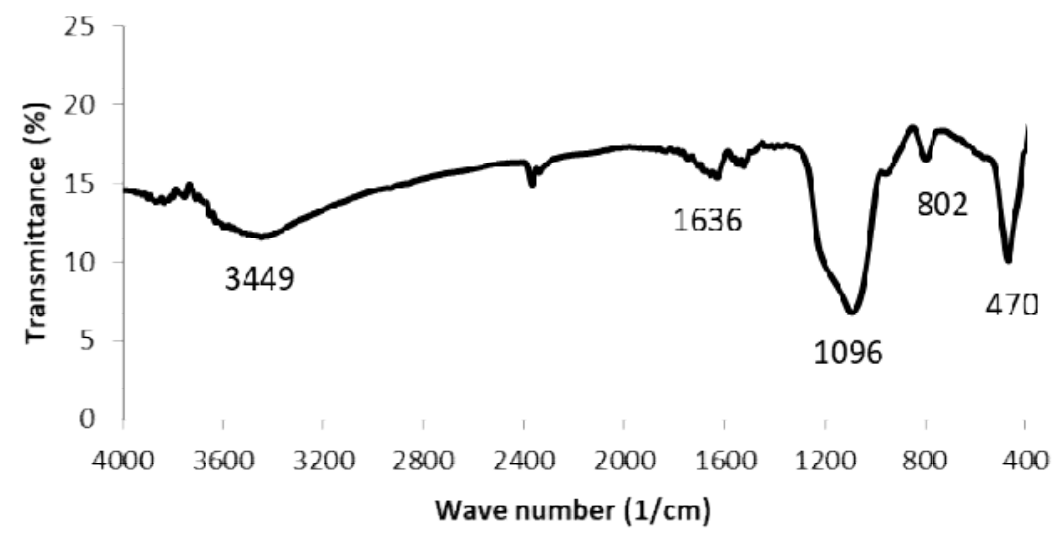

Fig.-1: FTIR Spectrum of Silica from Sidoarjo Mud

\section{Characterization of Bovine Bone Gelatin}

The identification of gelatin functional groups obtained from the extraction of bovine bone can be done using FTIR. Trisunaryanti et $\mathrm{al}^{19}$ indicate 5 amide regions which are typical groups of gelatin, namely amide A, amide B, amide I, amide II and amide III. Amide A appears at a wavenumber of about 3600$3400 \mathrm{~cm}^{-1}$ which shows the stretching vibration of $\mathrm{NH}$ and $\mathrm{OH}$ groups. Amide $\mathrm{B}$ appears at wavenumbers $3000-2800 \mathrm{~cm}^{-1}$ which is a stretching vibration of $\mathrm{CH}_{2}$. Amide I appears at the wave number $1700-1600$ $\mathrm{cm}^{-1}$ which shows the stretching vibration of $\mathrm{C}=\mathrm{O}$ and the bending vibration of $\mathrm{NH}$ into the plane. Amide II appears at wave number $1575-1480 \mathrm{~cm}^{-1}$ which shows bending vibration of $\mathrm{NH}$ into the plane and stretching vibration of CN. Amide III appears at wave number $1240-670 \mathrm{~cm}^{-1}$ which shows a combination of stretching vibration of $\mathrm{CN}$ and $\mathrm{NH}$ deformation from amide linkage. The absorption that arises from the wagging vibration of $\mathrm{CH}_{2}$ functional groups from the glycine and proline side chains.



Fig.-2: FTIR Spectrum of Bovine Bone Gelatin

Based on Fig.-2, amide A is observed at wave number $3410 \mathrm{~cm}^{-1}$ which shows the stretching vibrations of $\mathrm{NH}$ and $\mathrm{OH}$, while amide B absorption at wave number $2924 \mathrm{~cm}^{-1}$ shows the asymmetry stretching vibration of $\mathrm{CH}_{2}$ and at $2855 \mathrm{~cm}^{-1}$ shows symmetry stretching of $\mathrm{CH}_{2}$. The amide I appear on uptake of $1659 \mathrm{~cm}^{-1}$. Amide I vibration is stretching of $\mathrm{C}=\mathrm{O}$ which is coupled with stretching of $\mathrm{CN}$. This amide I show the characteristic of the coil gelatin structure. The appearance of the peak in the amide I region indicates that the triple helix structure of collagen has turned into a coil ${ }^{20}$. The amide II region appears in 
RASĀYAN J. Chem.

Vol. 13 | No. 1 |723-732| January - March | 2020

the absorption of $1551 \mathrm{~cm}^{-1}$ which shows bending vibration of $\mathrm{NH}$ and stretching vibration of $\mathrm{CN}$. Bovine bone gelatin also shows the presence of an amide III band at $1242 \mathrm{~cm}^{-1}$ uptake which indicated the loss of the molecular triple helix state and transformation of $\alpha$ helical into irregular rolls in consequence of collagen denaturation into gelatin. Based on the result of interpretation with FTIR in Fig.-2, it can be observed that extracted gelatin contains the main group of gelatin. The result of this study is following Pongsendana et $a 1^{9}$ so that it can be said that the gelatin extraction from bovine bone was successfully worked. Therefore, the gelatin can be applied as a template in the synthesis of mesoporous silica (MS) since the gelatin has many amino functional groups $\left(-\mathrm{NH}_{2}\right)$ which will interact strongly with silanol (Si$\mathrm{OH})$ groups in silicate groups through hydrogen bonds to form material mesoporous silica (MS).

\section{Characterization of Mesoporous Silica (MS) Material}

Characterization by FTIR was carried out to determine the functional groups found in MS both before and after the calcination process and confirm the success of the calcination process in removing the template from neutral (non-ionic) surfactants, namely gelatin. In the synthesis of MS material three variations in the ratio of the weight of silica/gelatin: 4, 6 , and 8 were carried out to produce MS4, MS6, and MS8. Fig.3 showed the FTIR spectra of MS4, MS6, and MS8 before and after calcination. It was intended to prove that through the calcination process, it could be eliminated from the gelatin template.

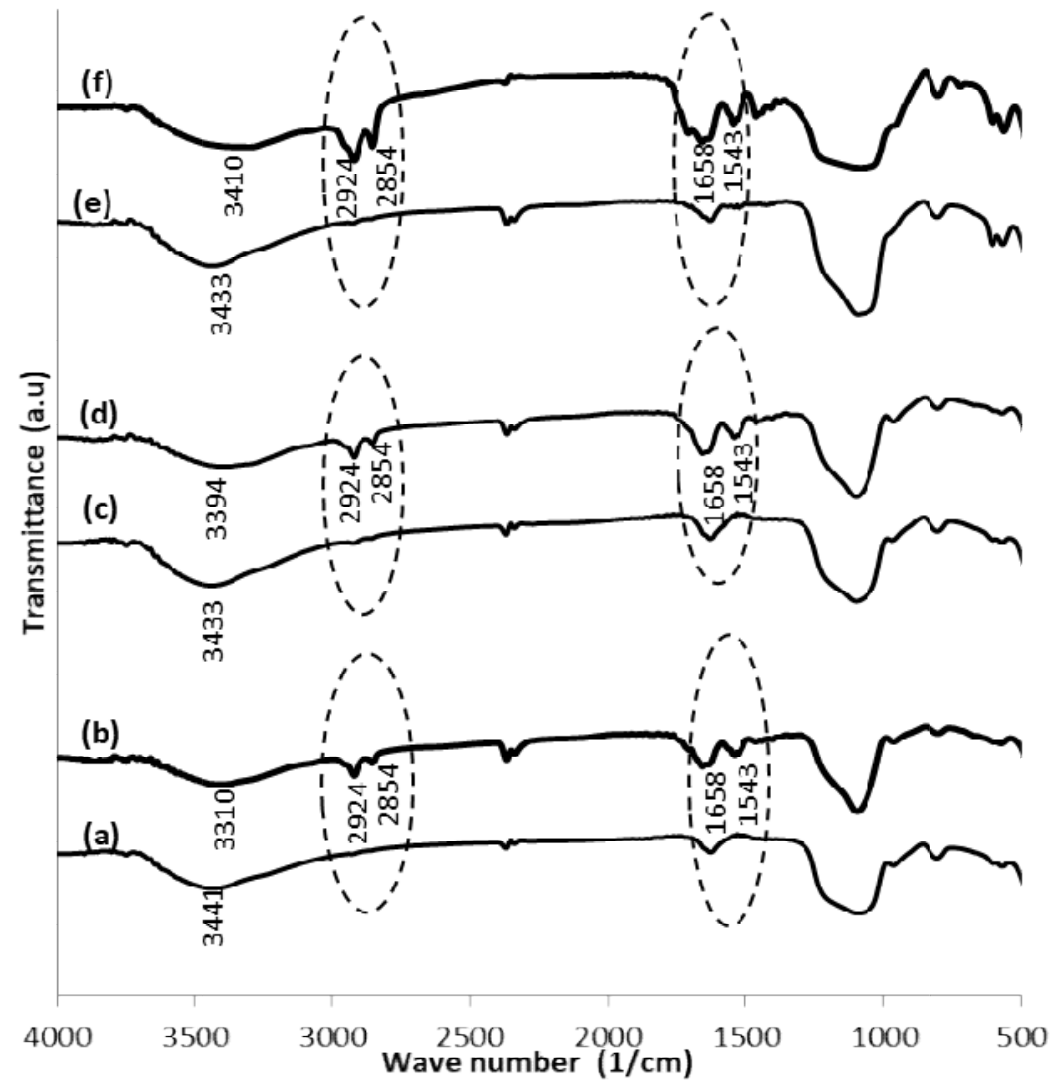

Fig.-3: FTIR Spectra MS4 (a) After (b) Before Calcination; MS6 (c) After (d) Before Calcination; and MS8 (e) After (f) Before Calcination

From Fig.-3, FTIR spectra show appearance typical vibration of gelatin and silica. Gelatin was indicated as peaks at 2924, 2854, and $1543 \mathrm{~cm}^{-1}$ that were stretching vibration of $\mathrm{CH}_{2}$ and bending vibration of $\mathrm{NH}$. Peaks indicated as the typical peak of silica appeared respectively at 3310,3394 , and $3410 \mathrm{~cm}^{-1}$ (stretching of Si-OH), 1636 and $1659 \mathrm{~cm}^{-1}$ (bending of Si-OH), 1096 and $1103 \mathrm{~cm}^{-1}$ (asymmetry stretching of Si-O-Si), $802 \mathrm{~cm}^{-1}$ (symmetry stretching of Si-O-Si), 463 and $471 \mathrm{~cm}^{-1}$ (bending of Si-O-Si). This outcome was similar to the result obtained by Yang et $a{ }^{21}{ }^{21}$ It can be concluded that the synthesis of 
RASĀYAN J. Chem.

Vol. 13 | No. 1 |723 - 732| January - March | 2020

material MS4, MS6, and MS8 has been successfully carried out by showing the existence of typical groups of gelatin prints and silicate frames in FTIR spectra. Formation of frames in MS4, MS6, and MS8 with gelatin template is caused by the occurrence of hydrogen bonds between amino-functional groups ($\mathrm{NH}_{2}$ ) in gelatin with silanol ( $\left.\mathrm{Si}-\mathrm{OH}\right)$ groups in sodium silicate. While the variation in the ratio of the weight of silica/gelatin does not have much effect on the wavenumber of vibrational peak that appears, but only affects the peak intensity.

After calcination, the FTIR spectra of gelatin characteristics was disappeared. This occurrence indicated that the calcination process was powerful to eliminate gelatin from the MS framework. On the calcination, the increasing weight ratio of silica/gelatin resulted in the typical peak intensity gelatin that appears to be weakened even disappeared. Gelatin is one of the organic compounds that will be damaged, lost or degraded at very high temperatures, for example, $550{ }^{\circ} \mathrm{C}$. Also, inorganic compounds will be difficult to damage, loss or degrade even when carried out at very high temperatures. The MS with minimum gelatin content after calcination had MS8. The elimination of the template was done to make the formation of the pore of MS. From the information it can be deduced that the calcination process has been successfully carried out. This result was in agreement with the result obtained by Triyono et $a 1^{6}$

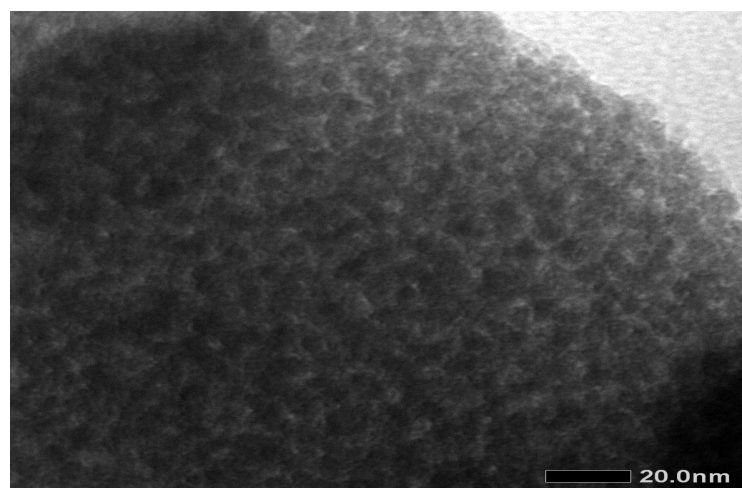

Fig.-4: TEM Image of MS8

The analysis using the Transmission Electron Microscope (TEM) instrument aims to determine the morphology and regularity of the synthesized MS8. Fig.-4. shows TEM image of the resulted MS8. The dark part of the TEM image shows the presence of solids or the dominance of the presence of surfactants which are the pore walls. On the other hand, in the bright part of the TEM image, there is a part that has no solid or a small amount of surfactant so that it is a hollow space. When viewed from its regularity, the synthesized MS8 does not show pore regularity. This synthesized MS8 only shows pore regularities such as wormhole-like because bovine bone gelatin which is used as a non-ionic template has a low order. This is under the study reported by Wang et $\mathrm{al}^{8}$ that MS has a pore shape like a wormhole.

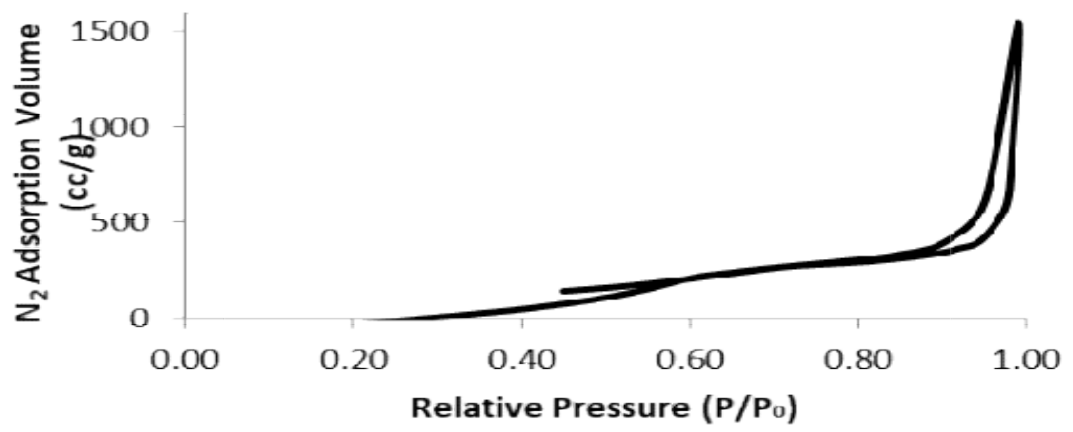

Fig.-5: $\mathrm{N}_{2}$ Adsorption-desorption Isotherm of MS8

The presence of hysteresis loops in Fig.-5 shows the mesopore character in the MS8 material with the $\mathrm{N}_{2}$ gas adsorption-desorption isotherm pattern leading to type IV classification (IUPAC standard). The 
RASĀYAN J. Chem.

Vol. 13 | No. 1 |723-732| January - March | 2020

pattern of adsorption-desorption isotherm of $\mathrm{N}_{2}$ gas of type IV is the character of adsorption-desorption of mesoporous material with its porous wall having a relatively strong tensile force to the liquid. Hysteresis loops formed in the $\mathrm{P} / \mathrm{P}_{0}$ area $0.88-0.99$ in Fig.-5 are the result of condensation and evaporation of mesoporous capillaries which occur at different relative pressures. The hysteresis loops are included in the classification of $\mathrm{H} 3$ type hysteresis loops which do not show the limitations of adsorption at relatively high pressures. The appearance of hysteresis loops by the presence of capillary condensation on mesoporous structures shows that the MS8 material has been successfully synthesized.

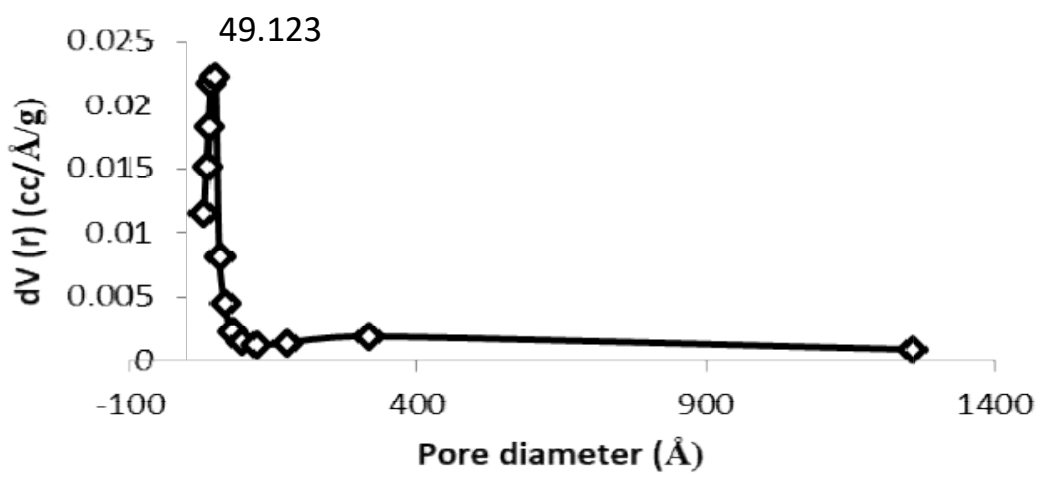

Fig.-6: Pore Size Distribution of MS8

Based on the desorption analysis of $\mathrm{N}_{2}$ gas, it can be seen that the pore distribution scattered in the MS8 material is in the range of 31-174 $\AA$ (3.1-17.4 nm). The adsorption-desorption isotherm pattern is supported by pore size distribution data. The pore size classification according to IUPAC states that the diameter of mesoporous material is 2-50 nm. Fig.-6 shows that the MS8 has the most dominant pore diameter distribution at $49.123 \AA(4.9 \mathrm{~nm})$. From these data, it can be observed that the synthesized MS8 has a high pore diversity in the mesopore region. Whereas the specific surface area of the MS8 material based on BET analysis is $666.762 \mathrm{~m}^{2} \mathrm{~g}^{-1}$. This high surface area indicates that the synthesized MS8 material is very well used as a catalyst support or carrier material. In addition, this MS material has a pore volume of $0.46 \mathrm{~cm}^{3} \mathrm{~g}^{-1}$.

\section{Characterization of Co/MS8 Material}

The XRF analysis result shows that the metal consisted of Co/MS8 is $\mathrm{Si}, \mathrm{Ca}, \mathrm{P}, \mathrm{Fe}, \mathrm{Co}, \mathrm{Ni}$, and others of $78.40 \%, 8.54 \%, 2.30 \%, 1.35 \%, 6.11 \%, 2.31 \%$, and $0.99 \%$ respectively. It can be seen that there are three most dominant elements which are compositions of $\mathrm{Co} / \mathrm{MS} 8$ catalysts namely $\mathrm{Si}, \mathrm{Ca}$, and $\mathrm{Co}$. The composition of the $\mathrm{Si}$ element contained in the Co/MS8 catalyst is $78.40 \%$, while the Co element is only $6.11 \%$. The composition of the Si element in the Co/MS8 catalyst is the most because the MS8 material is composed of Si-O-Si and Si-OH molecules shown by the FTIR spectrum. The presence of Ca element of $8.54 \%$ and $\mathrm{Ni}$ of $2.31 \%$ is due to sodium silicate used from silica extracted in the synthesis of MS8 already containing $\mathrm{Ca}$ and $\mathrm{Ni}$ elements. The Co element content of $6.11 \%$ indicates that the metal impregnation process in the MS8 sample has been successfully carried out. In developing metal Co with wet impregnation method, the Co metal which is intended to be treated is $8 \%(w / w)$, but after analysis using the XRF method, it is known that the Co element is embedded in MS8 is $6.11 \%$. This is due to the occurrence of leaching on the Co metal which was carried out on MS8.

Based on the results of calculations regarding the determination of acidity, it was found that the acidity of the MS8 and Co/MS8 was 4.9 and $14.7 \mathrm{mmol} / \mathrm{g}$. The Co/MS8 had higher acidity than the MS8. The presence of Co metal in the Co/MS8 increases the number of acid sites of the catalyst. The increase in acidity is caused by the presence of empty d orbitals on Co metal provides Lewis acid site. Blank orbitals in the embedded metal will act as Lewis acids by accepting a pair of free electrons from $\mathrm{NH}_{3}$.

\section{Characterization of $\mathrm{Co}-\mathrm{NH}_{2} / \mathrm{MS8}$ Material}

According to $\mathrm{Wu}$ et $\mathrm{al}^{10}$, Cao et $\mathrm{al}^{22}$, and Triyono et $\mathrm{al}^{6}$ state that the addition of an amine group to the MCM-41 aims to minimize the possibility of leaching from the catalyst. In Fig.-7 shows that the MS8 
RASĀYAN J. Chem.

Vol. 13 | No. 1 |723 - 732| January - March | 2020

FTIR spectra that have been carried out by $\mathrm{NH}_{2}$ group grafting from the 3-APTMS compound have a $\mathrm{CH}_{2}$ group vibration peak at wave number 2932 and $2862 \mathrm{~cm}^{-1}$, scissoring vibration of $\mathrm{NH}_{2}$ group at wave number $1528 \mathrm{~cm}^{-1}$, and vibration of $\mathrm{CN}$ at wave number $1096 \mathrm{~cm}^{-1}$. Ortiz et al ${ }^{23}$ state that the new groups that appear in the MCM-41 functionalized amines can be estimated qualitatively based on groups found in 3-APTMS compounds. They reported that the MCM-41 functionalized amine would show the vibration of the $\mathrm{CH}_{2}$ group from the 3-APTMS carbon chain at wavenumbers 2990 and $2890 \mathrm{~cm}^{-1}$. Scissoring vibration of $\mathrm{NH}_{2}$ groups at wave number $1560 \mathrm{~cm}^{-1}$ while the vibration of $\mathrm{C}-\mathrm{N}$ arises in the area of 1000 $1200 \mathrm{~cm}^{-1}$. Triyono et al ${ }^{7}$ state that the high vibration of $\mathrm{O}-\mathrm{H}$ from water at $1635.64 \mathrm{~cm}^{-1}$ can close the vibrations of the $\mathrm{NH}_{2}$ group at wave number $1560 \mathrm{~cm}^{-1}$. Scissoring vibration of the $\mathrm{NH}_{2}$ group at wave number $1560 \mathrm{~cm}^{-1}$ appears with a very small intensity. This can be explained by the addition of 3-APTMS with a very little amount, with a $5 \% \mathrm{~N} / \mathrm{Si}$ ratio added during the grafting process.

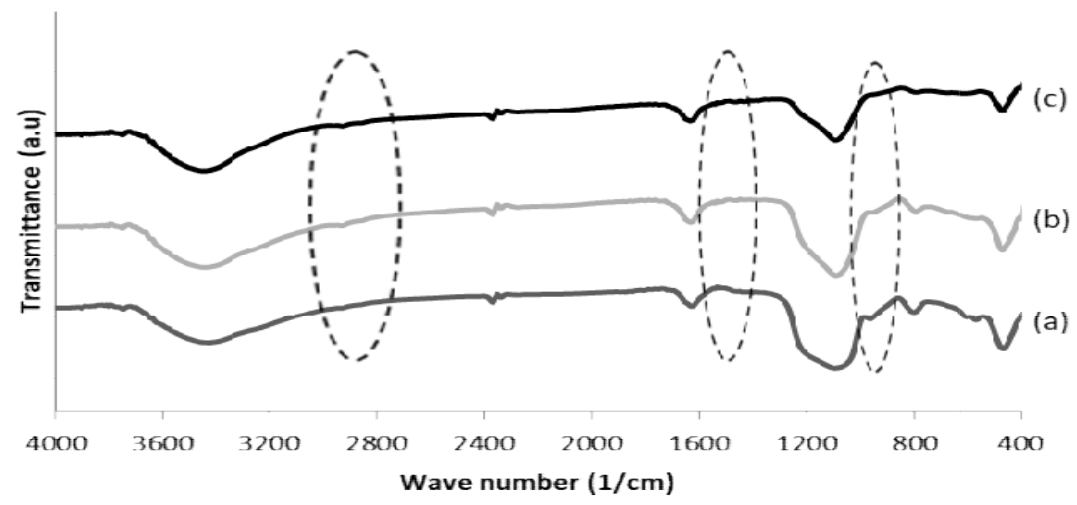

Fig.-7: FTIR Spectra of (a) MS8, (b) $\mathrm{NH}_{2} / \mathrm{MS} 8$, (c) $\mathrm{Co}-\mathrm{NH}_{2} / \mathrm{MS} 8$

\section{Activity Test of the Co- $\mathrm{NH}_{2} / \mathrm{MS8}$ Catalyst}

Table- 1 and 2 show the activity of the thermal, physical mixture of Co/MS8 and $\mathrm{NH}_{2} / \mathrm{MS} 8$ catalyst, and $\mathrm{Co}-\mathrm{NH}_{2} / \mathrm{MS} 8$ bifunctional catalyst on hydrocracking of the used cooking oil. The result showed if using catalyst produced liquid fraction higher than only using the thermal process (without catalyst). This condition could be described by the fact that the hydrocracking by thermal happened via a radical mechanism that can generate more gas fraction ${ }^{24}$. The highest conversion of liquid products was performed using the $\mathrm{Co}-\mathrm{NH}_{2} / \mathrm{MS} 8$ bifunctional catalyst. It is because there was an impregnation of Co in the MS8 that can increase the acidity of catalyst for hydrocracking, and was combined with the functionalization of $\mathrm{NH}_{2}$ molecule from 3-APTMS that bind directly to the free fatty acids contained in used cooking oil. The highest liquid product was $97.62 \mathrm{wt} \%$ which consisted of gasoline and diesel oil fraction of 3.02 and 46.86 wt.\%. This yield is higher than the activity of the catalyst of the physical mixture of $\mathrm{Co} / \mathrm{MS} 8$ and $\mathrm{NH}_{2} / \mathrm{MS} 8$ which only produces the liquid product of $11 \mathrm{wt} . \%$. This is because of the catalysts work individually. The $\mathrm{NH}_{2} / \mathrm{MS} 8$ catalyst works in the process of esterification of free fatty acids in used cooking oil, whereas the Co/MS8 catalyst works in the hydrocracking process. Meanwhile, the $\mathrm{Co}-\mathrm{NH}_{2} / \mathrm{MS} 8$ bifunctional catalyst works synergistically in the process of esterification and hydrocracking simultaneously. This result was in agreement with the result obtained by Kandel et al. ${ }^{16}$

Table-1: Product Distributions of used Cooking Oil Hydrocracking

\begin{tabular}{c|c|c|c}
\hline \multirow{2}{*}{ Catalyst } & \multicolumn{3}{|c}{ Conversion (wt.\%) } \\
\cline { 2 - 4 } & Liquid Fraction* & Gas Fraction & Cokes \\
\hline Without catalyst & 8 & 87.80 & 4.20 \\
\hline $\mathrm{Co} / \mathrm{MS} 8$ and $\mathrm{NH}_{2} / \mathrm{MS} 8$ & 11 & 65.40 & 23.60 \\
\hline $\mathrm{Co}-\mathrm{NH}_{2} / \mathrm{MS} 8$ & 97.62 & 0 & 2.38 \\
\hline
\end{tabular}

Note: * Calculated from (Liquid Product Weight/Substrate Weight) x 100\% 
RASĀYAN J. Chem.

Vol. 13 | No. 1 |723 - 732| January - March | 2020

Table-2: Catalyst Selectivity towards Gasoline and Diesel Oil Fraction

\begin{tabular}{c|c|c|c}
\hline \multirow{2}{*}{ Catalyst } & \multicolumn{3}{|c}{ Fractions in a Liquid Product (wt.\%) } \\
\cline { 2 - 4 } & Gasoline $\left(\mathrm{C}_{5}-\mathrm{C}_{12}\right)^{\mathrm{a}}$ & Diesel $\left(\mathrm{C}_{13}-\mathrm{C}_{17}\right)^{\mathrm{b}}$ & Others $^{\mathrm{c}}$ \\
\hline Without catalyst & 0.12 & 1.02 & 6.86 \\
\hline $\mathrm{Co} / \mathrm{MS} 8$ and $\mathrm{NH}_{2} / \mathrm{MS} 8$ & 8.94 & 1.05 & 1.01 \\
\hline $\mathrm{Co}-\mathrm{NH}_{2} / \mathrm{MS} 8$ & 3.02 & 46.86 & 47.74 \\
\hline
\end{tabular}

Notes: ${ }^{\mathrm{a}}$ ) Calculated from (GC Area of $\mathrm{C}_{5}-\mathrm{C}_{12} \mathrm{x} \%$ Liquid Product)

b) Calculated from (GC Area of $\mathrm{C}_{13}-\mathrm{C}_{17} \mathrm{x} \%$ Liquid Product)

c) Others Compounds except for Gasoline and Diesel Oil Fractions from (Total Liquid $-(a+b)$ )

\section{CONCLUSION}

Synthesis of mesoporous silica (MS) from silica Sidoarjo mud and bovine bone gelatin as a template had been effectively carried out. MS8 has minimum gelatin content after calcination. MS8 had an acidity, pore diameter, specific surface area and pore volume of $4.9 \mathrm{mmol} \mathrm{g}{ }^{-1}, 4.9 \mathrm{~nm}, 666.762 \mathrm{~m}^{2} \mathrm{~g}^{-1}, 2.67 \mathrm{~cm}^{3} \mathrm{~g}^{-}$ ${ }^{1}$, respectively. The Co metal content loaded on the MS8 by XRF was $6.11 \%$ and Co/MS8 had an acidity of $14.7 \mathrm{mmol} \mathrm{g}$. The $\mathrm{Co}-\mathrm{NH}_{2} / \mathrm{MS} 8$ of the bifunctional catalyst produced the highest liquid products of 97.629 wt. \% with the selectivity for gasoline and diesel fraction of 3.02 and $46.86 \mathrm{wt} . \%$ on hydrocracking of used cooking oil.

\section{ACKNOWLEDGMENT}

The author thanks The Indonesian Ministry of Research, Technology, and Higher Education for Financial support under the scheme of PDUPT research grant 2019 (Contract Number: 2524/UN1.DITLIT/DITLIT/LT/2019).

\section{REFERENCES}

1. H. Setyawan and R. Balgis, Asia-Pacific Journal Chemical Engineering, 7(3), 448 (2011), DOI: 10.1002/apj.593

2. E.A. Karakhanov, A.P. Glotov, A. G. Nikiforova, A.V. Vutolkina, A.O. Ivanov, S.V Kardashev, A.L. Maksimov, and S.V. Lysenko, Fuel Process Technology, 153, 50(2016), DOI: 10.1016/j.fuproc.2016.07.023

3. A.B. Majid, W. Trisunaryanti, Triyono, and K. Dewi, The 6th International Symposium on Nano and Supramolecular Chemistry, 10-14 ${ }^{\text {th }}$ August 2014, Bali.

4. S. Lin, L. Shi, M.M.L. Riberio Carrott, P.J.M. Carrott, J. Rocha, M.R. Li and X.D. Zou, Microporous and Mesoporous Material, 142(2-3), 526 (2011), DOI: 10.1016/j.micromeso.2010.12.043

5. A. Masykuroh, W. Trisunaryanti, I. I. Falah and Sutarno, International Journal of ChemTech Research, 9, 598(2016).

6. Triyono, H.M. Khoiri, W. Trisunaryanti, and K. Dewi, IOSR Journal of Applied Chemistry, 8(8), 5053 (2015), DOI: 10.9790/5736-08825056

7. H.I.M. Ortiz, A.M. Silva, L.A.G. Cerda, G. Castruita, and Y.A.P. Mercado, Journal of the Mexican Chemical Society, 57(2), 73 (2013), DOI: 10.29356/jmcs.v57i2.215

8. X. Wang, G. Zhaou, H. Zhang, S. Du, Y. Xu and C. Wang, Journal Non-Crystalline Solids, 357(15), 3027-3030 (2011), DOI: 10.1016/j.jnoncrysol.2011.04.009

9. M. Pongsendana, W. Trisunaryanti, F.W. Artanti, I.I. Falah and Sutarno, Korean Journal of Chemical Engineering, 34(10), 2591(2017), DOI:10.1007/s11814-017-0165-3

10. X.L. Wu, C.Y. Yang, X. Chen and X.C. Zheng, Applied Surface Science, 270, 590 (2013), DOI: 10.1016/j.apsusc.2013.01.090

11. H. Kusumastuti, W. Trisunaryanti, I.I. Falah and M.F. Marsuki, Rasayan Journal of Chemistry, 11(2), 522 (2018), DOI: 10.31788/rjc.2018.1122061

12. I. Salim, W. Trisunaryanti, Triyono, and Y. Arryanto, International Journal of ChemTech Research, 9, 492(2016).

13. S.S. Bhoware and A.P. Sigh, Molecular Catalysis, 266(1), 118 (2007), DOI:10.1016/j.molcata.2006.09.031

14. P. Iliade, I. Miletto, S. Coluccia, and G. Berlier, Research on Chemical Intermediates, 38(3-5), 786 (2012), DOI:10.1007/s11164-011-0417-5 
RASĀYAN J. Chem.

Vol. 13 | No. 1 |723 - 732| January - March | 2020

15. R.I. Kusuma, J.P. Hadinoto, A. Ayucitra, F.E. Soataredjo, and S. Ismadji, Applied Clay Science, 74, 121 (2013), DOI:10.1016/j.clay.2012.04.021

16. K. Kandel, C. Frederickson, E.A. Smith, Y.J. Lee, and I.I. Slowing, ACS Catalysis, 3(12), 2750 (2013), DOI: $10.1021 / \operatorname{cs} 4008039$

17. Triyono, W. Trisunaryanti, A.D. Putri and K. Dewi, Asian Journal of Chemistry, 30(5), 954 (2018), DOI: 10.14233 /ajchem.2018.20979

18. W. Trisunaryanti, I.I. Falah, D.R. Prihandini, and M.F. Marsuki, Rasayan Journal of Chemistry, 12, 1523(2019), DOI: 10.31788/RJC.2019.1235297.

19. W. Trisunaryanti, P.S. Lisna, I. Kartini, Sutarno, I.I. Falah and Triyono, Asian Journal of Chemistry, 28(5), 997 (2016), DOI: 10.14233/ajchem.2016.19561

20. M.H. Uriarte-Muntoya, H. Santacruz-Ortega, F.J. Cinco-Moroyoqui, O. Rouzaud-Sandez, M. Plascencia-Jatomea, and J.M. Ezquerra-Brauer, Food Research International, 44(10), 3246 (2011), DOI: $10.1016 / j$.foodres.2011.08.018

21. X. Yang, S. Liao, Z. Liang, Y. Li and L. Du, Microporous and Mesoporous Materials, 143(2-3), 263 (2011), DOI: 10.1016/j.micromeso.2011.02.027

22. J. Cao, Y. Wu, Y. Jin, P. Yilihan and W. Huang, Journal of the Taiwan Institute of Chemical Engineers, 45(3), 860 (2014), DOI:10.1016/j.jtice.2013.09.011

23. H.I.M. Ortiz, Y.P. Mercado, J.A.M. Silva, Y.O. Maldonado, G. Castruita, And L.A.G. Cerda, Ceramics International, 40(7), 9703 (2014), DOI:10.1016/j.ceramint.2014.02.051

24. F. W. Artanti, W. Trisunaryanti, M. Pongsendana, Triyono, I. I. Falah and M. F. Marsuki, Rasayan Journal of Chemistry, 11, 1433(2018), DOI: 10.31788/RJC.2018.1143073.

[RJC-5514/2019] 